\title{
iSTAR First Light: Characterizing Astronomy Education Research Dissertations In The iSTAR Database
}

\author{
Stephanie J. Slater, Ph.D., CAPER Center for Astronomy \& Physics Education Research, USA \\ Coty B. Tatge, A.B.D., University of Wyoming, USA \\ Paulo S. Bretones, Ph.D., São Carlos Federal University, Brazil \\ Timothy F. Slater, Ph.D., University of Wyoming, USA \\ Sharon P. Schleigh, Ed.D., East Carolina University, USA \\ David McKinnon, Ph.D., Edith Cowen University, Australia \\ Inge Heyer, Ph.D., Loyola Marymount, USA
}

\begin{abstract}
There is widespread interest among discipline-based science education researchers to situate their research in the existing scholarly literature base. Unfortunately, traditional approaches to conducting a thorough literature review are unduly hindered in astronomy education research as the venues in which scholarship is reported are fragmented and widely dispersed across journals of varying disciplines. The international STudies of Astronomy education Research (iSTAR) online repository is the result of a concerted international community effort to collect and categorize existing research from peer-reviewed journal articles, dissertations/theses, and grey literature. In a "first light" survey of over 300 U.S. dissertations, we find: (i) work in AER dates back to 1923; (ii) the number of extant dissertations is far greater than anticipated; (iii) research methods definitions have evolved; and (iv) most work has studied participants' broad knowledge rather than specific learning targets. The surprisingly wide breadth of rarely cited research motivates us to collect more AER from across international and cross-disciplinary sources.
\end{abstract}

Keywords: Astronomy Education Research; Science Education Literature Review

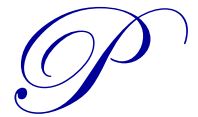

rogress in astronomy education research - heretofore referred to simply as AER - requires that we first understand the scope of what is known about teaching and learning astronomy content across diverse settings, and what is not. Unfortunately, AER is a broad scientific discipline in which the existing landscape is particularly difficult to comprehensively grasp. Unlike the field of traditional astronomy in which research is conducted nearly exclusively by individuals who hold the exclusive identities of "professional astronomers," AER is conducted by individuals representing a wide variety of academic settings and affiliations, including professional astronomers, astronomy education researchers, planetarium operators, cognitive scientists, psychologists, anthropologists, science educators, science education researchers, teacher educators, policy makers, museum educators, curriculum developers, outreach enthusiasts, and publishers (Slater, Slater, Heyer, \& Bailey, 2015). These individuals most often present findings in research journals tightly related to their own professional fields, hindering knowledge transfer amongst communities of researchers and practitioners. Absent the ability to accurately describe the existing research landscape we often swirl in the vortex of our preconceptions, stymied in our efforts because we do not have a grasp on what we do and do not know, about the ways that humans currently and might possibly come to learn astronomical concepts.

Isolation caused by disciplinary silos is magnified by other factors that drive AER toward domination by a few voices, from a few research settings, using a limited set of theoretical frameworks and methodologies. Works published as dissertations and thesis, in the pre-digital era, from lesser known journals coming from non-Western countries, or that are hidden behind paywalls are disadvantaged in their ability to influence the AER research agenda. Researchers from smaller institutions and from developing nations experience the greatest barriers to access these community resources 
and, thus are disproportionately affected by the lack of access to prior research and by difficulties in disseminating their work. This situation unnecessarily diminishes scholars' opportunities to collaborate and to influence the international research discussion. We would further assert that even dominant researchers are hindered from engaging in fruitful collaborations and research by the existing barriers to accessing the widely distributed, difficult to acquire literature relevant to the field.

The lack of diverse collaborations and cross-pollinations within the field is not a merely academic problem. Rather, it may help to explain much of what we have seen in the existing Western literature base. That is to say, while we have experienced a large production of research literature, we continue to struggle to sufficiently improve student learning in astronomy. For instance, when we look at recent reports of students' conception of the Sun-Earth-Moon system (Slater, 2014), we see little improvement from reports that date back to the early years of AER (Ralya \& Ralya, 1940). Despite what appears to be an excess of research on the topic (Lelliott \& Rollnick, 2010), Western students still cannot explain the cause of the seasons. While there are a few possible explanations for these results, one possible explanation may be that the dominant perspectives in the field have converged on an AER canon that is a self-validating reduction. If so, one possible solution may be to look beyond the most cited literature, and to mine for new insight in the vast body of work provided our colleagues, who may have considered these learning challenges from uncommon perspectives, using unfamiliar instructional techniques, in diverse cultural settings, employing atypical methodologies.

Given this potential, we were encouraged to create a more efficient pathway for international researchers to build from a wider diversity of AER scholarship. After determining that there is indeed evidence that, even in research university settings, there is a great deal of difficulty in obtaining existing research publications, we constructed the international

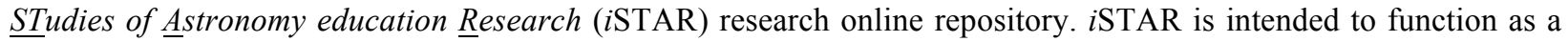
research instrument for the AER community, eventually housing the majority of AER publications produced across the international setting. This paper reports on the instrument's "first light" functionality as tested on a small sample of papers. A term borrowed from astronomy, "first light" is the first image taken with a new research instrument, and while never the most important or most meaningful image that will ever be taken, it is usually of a target that is well known, and perhaps of sentimental value to the community. In this case, iSTAR's first light image is of the body of existing AER dissertations and theses produced in the United States, a sample that we initially believed would number approximately 50 works.

This paper describes our process of developing the $i$ STAR database, and provides a glimpse of what the database may be capable of via a first light look at over 300 AER doctoral dissertations and graduate theses from the United States related to astronomy education. Future steps for the $i$ STAR project and opportunities to contribute to the project are described in the discussion section.

\section{BACKGROUND AND CONTEXT}

Prior to constructing iSTAR a review was conducted of existing literature reviews in AER. The intention was to determine the extent to which these reviews included similar works, and the extent to which the cited works were easily accessed online and through the libraries of research institutions. For the purposes of the efforts described here, our survey of the pre-existing reviews is constrained to six published reviews. A summary of the selected reviews is shown in Table 1.

Wall (1973) was the first to publish an extensive summary of research related to astronomy education in a peerreviewed journal. The works he summarized were primarily theses and dissertations created by graduate students completing a University degree. It should be noted that in the narrative of his paper, Wall states that 54 of the 58 reviewed works were dissertations or theses. In the "References" section of his paper, only 36 works are clearly so identified. Wall separated the included works by the nature of each study's participants (e.g., elementary, secondary, and college-level, teachers) and by the type of study (e.g., status studies, achievement gains, and curriculum summaries). His analysis was not restricted to a content domain of astronomy nor was it restricted to a geographic region as he included research reports he could find outside of the United States' borders. Wall's report was critical to the field of astronomy education research at that time in that it was the first of its kind to attempt to collect works, describe them, then propose recommended future directions to the field. 
Table 1. Summary of Peer-Reviewed Literature Reviews in Astronomy Education

\begin{tabular}{l|l|l|l|l|l|c}
\hline Paper & Year & Content Scope & $\begin{array}{c}\text { Geographic } \\
\text { Scope }\end{array}$ & \multicolumn{1}{|c|}{ Document Types } & Analysis Method & $\begin{array}{c}\text { Number of } \\
\text { Papers Included }\end{array}$ \\
\hline Wall & 1973 & All & International & $\begin{array}{l}\text { Theses \& } \\
\text { Dissertations }\end{array}$ & $\begin{array}{l}\text { Annotated } \\
\text { Bibliography }\end{array}$ & 58 \\
\hline $\begin{array}{l}\text { Bailey } \\
\& \text { Slater }\end{array}$ & 2003 & All & International & $\begin{array}{l}\text { Peer-reviewed Work \& } \\
\text { Sadler's Dissertation }\end{array}$ & $\begin{array}{l}\text { Annotated } \\
\text { Bibliography }\end{array}$ & $<100$ \\
\hline Fraknoi & 2007 & All & International & $\begin{array}{l}\text { Peer-reviewed Works } \\
\text { (AER Journal Papers) }\end{array}$ & $\begin{array}{l}\text { Descriptive } \\
\text { Statistics }\end{array}$ & $\begin{array}{c}\text { Approximately } \\
100\end{array}$ \\
\hline Brazell & 2009 & Planetarium & U.S. & $\begin{array}{l}\text { Peer-reviewed, } \\
\text { Dissertations }\end{array}$ & $\begin{array}{l}\text { Quantitative Meta- } \\
\text { Analysis }\end{array}$ & 19 \\
\hline Lelliott & 2010 & $\begin{array}{l}\text { Broad Astronomy } \\
\text { Content }\end{array}$ & International & Peer-reviewed & Research Synthesis & 103 \\
\hline Bretones & 2011 & All & International & IAU Proceedings & $\begin{array}{l}\text { Descriptive } \\
\text { Statistics }\end{array}$ & 283 \\
\hline
\end{tabular}

Wall's work provided important context for the iSTAR project. First, Wall's sample indicated that given a steady rate of production, there might be as many as 100 dissertations and theses available for initially populating the repository, allowing the repository to be tested for functionality. However, of the theses and dissertations cited in Wall's review, the majority were not readily accessible through the normal channels at three U.S. research institutions. We consider this evidence that an online repository would greatly enhance access to these types of works.

Thirty years later, Bailey and Slater (2003) reviewed more than 100 studies referencing astronomy education topics. They included peer-reviewed articles, books, and web-based materials in their analysis. Including all content areas, the researchers organized the astronomy education research literature they could find into two broad categories: (i) student learning/understanding and (ii) instructional methods. The student learning category was then subdivided into a variety of conceptual learning targets including lunar phases, shape of the Earth, diurnal motion, cosmology, and astrobiology. Instructional methods were subdivided into personalized instruction, teaching conceptual understanding, collaborative learning, specific curriculum interventions, and planetarium learning. With regards to geographic scope, Bailey and Slater (2003) included all works located and related to astronomy education research largely within and somewhat beyond the borders of the United States. This is somewhat similar to work done in Australia by Broadfoot and Ginns (2005).

Like Wall did decades earlier, Bailey and Slater's goal was to create a landscape portrait of the field and make recommendations for further research efforts. However, the included works are exclusively from journals published in Western hemisphere countries. The two projects had surprisingly little overlap with only three of the works reviewed by Wall also appearing in the Bailey and Slater review. According to the authors, at the time of the review, works from other contexts and works cited by Wall were prohibitively difficult to find, despite efforts to obtain the remaining works through typical channels at a research-intensive university.

In 2007, Fraknoi and Wolff reviewed the progress and presented the descriptive statistics of articles appearing in the Astronomy Education Review journal. Their goal was not to review the entire field of AER, but to review articles appearing in the then relatively new journal to evaluate the journal's impact, its readership, and propose a pathway for the future of that peer-reviewed journal. At that time, there were approximately 100 peer-reviewed articles from the journal, which encompassed an international scope. Concluding that the Astronomy Education Review journal was having an important impact on the field of AER, the authors highlighted the frequency of articles from a specific institutions and subdivided the journal articles into themes including: teaching astronomy for K-12, use of technology in astronomy education, public outreach and education, and undergraduate and graduate-level education. This review is similar to that published by Bretones, Jafelice, and Horvath (2016).

The Fraknoi and Wolff review highlights the value of Internet-available journal like the Astronomy Education Review, in that it provided a locus for astronomy education researchers across international contexts to interact across open access to relevant works. The online, open access nature of the journal's publications supports research and practice across all settings with Internet access, serves as an important model for the newly developed iSTAR platform 
(Fraknoi, 2014). Two years later, Brazell (2009) reported on a meta-analysis of peer-reviewed articles and dissertations related to the efficacy of learning in the planetarium. Working from 19 United States publications Brazell quantitatively synthesized these planetarium studies by looking at effect sizes for achievement, attitude, grade level, subject matter, treatment type, control of instructor effect, group assignment, frequency of visits, and period (19601984 or 1985-2008). A comparison of the review completed by Brazell and with the Wall review (1973), which includes a large number of planetarium works indicated that in overlapping years, the papers differed in the publications captured for analysis. Rather than serving as evidence of poor scholarship, this serves as evidence of the difficulty inherent in locating relevant works, even for scholars who are thorough in their research.

A 2010 literature review by Lelliott and Rollnick included 103 peer-reviewed journal articles focused on studies occurring within the primary and secondary classrooms, museums, and/or among pre-and in-service teachers, as opposed to considering papers on postsecondary courses. They used peer-reviewed print based journal articles that included empirical, conceptual, and review papers, but purposefully excluded historical analyses, practitioner, and opinion pieces. They further synthesized all the works focusing on what they identified as the "big ideas" in astronomy. A comparison of this review with Bailey and Slater (2003) indicated that each paper captured works that were overlooked by the other review, when considering stated review parameters. Bailey and Slater were more likely to include works from lesser known U.S. sources, whereas Lelliott and Rollnick ventured into journals not captured in the Bailey and Slater review (e.g., Learning and Instruction Journal). This suggest that the dispersal of works in a wide variety of publications has the potential to expand our conception of the AER landscape.

Encompassing a much larger range of works, Bretones and Megid Neto (2011) looked for trends and synthesized characteristics across 283 published proceedings papers on astronomy education research presented at the International Astronomical Union meetings from 1988 to 2006. These proceedings papers are significantly longer and more detailed than typical abridged abstracts or poster presentations, which were not included in the analysis. The purpose of their study was to give recommendations for needed further research based on the statistics used to describe the field, using an international lens. Most relevant to the $i$ STAR project, none of the works included in this review were included in any of the other reviews. Bretones and Megid Neto reported that over $60 \%$ of the published proceedings were contributed by authors from outside of the United States. In comparison, the vast majority of works included in the previous reviews were contributed by U.S. authors. This provides warrant for the creation of pathways that highlight, and make accessible, non-U.S. research.

The existing reviews of astronomy education research described above vary greatly in their analysis methods, types of articles, and the number of articles included in their synthesis. Somewhat unexpectedly the reviews were universally non-exhaustive, as evidenced both by a significant lack of common overlap among the papers' reference lists, even when considering that the works differ in their intentions. Perhaps this is due to astronomy education researchers themselves having more interest in conducting limited and more focused reviews that serve their interests. For example, Adams and Slater (2000) published a highly constrained, but in-depth, review only considering what was known from astronomy education research only on those few topics listed in the United States' National Science Education Standards which would not normally be categorized as a comprehensive literature review. More likely, we attribute the lack of all-encompassing and synthetic reviews to the fact that librarians and the Internet have only recently made the task of finding work across the field significantly easier than it was in previous decades, although the increased access still does not extend to pre-digital works, works published in other nations, or works behind paywalls. This further adds warrant to the notion that a new effort to create a contemporary comprehensive list - if not a central online repository - would be valued and highly used by scholars in the field.

\section{METHOD}

Responding to the astronomy education community's need for a more useful astronomy education research literature collection, the $i$ STAR project began by selecting a test sample of papers and by determining a method for constructing the repository in such a way as to maximize its effectiveness for researchers. 


\section{Sample Selection}

For the initial $i$ STAR database survey, dissertations and graduate theses were chosen as the test sample. Many of these works are in danger of being lost as many, particularly those written prior to 2000, were never published beyond their initial committee review and printing. Today these works are often not considered to be peer-reviewed, but in earlier years more weight was given to the extraordinary amount of time and energy advisors and committee members contributed to the quality of the final publication. As an additional benefit, collecting the body of AER dissertations could give us an idea of the astronomy education "family tree" by taking note of who conducted degree work in astronomy education and who sat on those candidates' committees. Most importantly, the number of expected dissertations was fairly small. Given our collective experience in the field, we expected to find between 50 and 100 such papers produced in the United States.

While collecting community feedback on the repository structure sample collection began by scouring online library databases such as ProQuest, ERIC, university library repositories, Google Scholar and WorldCat using keywords such as "astronomy education", "constellations", "lunar phases", "seasons", "planetarium", and "cosmology". The citations list of all collected works were searched for references to additional papers that may not have appeared in any of the indexing systems. This system returned more than 400 dissertations and graduate theses. Citations for over 100 additional dissertations and theses were found, but we were unable to locate either the hardcopy paper or even the abstract. It is possible that more exist.

The content of each work was reviewed. If a work was deemed to be unrelated to astronomy education it was discarded. After that process, more than 300 dissertations and theses related to astronomy education remained. For the purposes of this "first light" study, only those works for which we had both a complete abstract and main narrative body were included in the analysis. This reduced the number of scholarly works in the initial sample to 252.

\section{iSTAR Categorization Scheme}

$i$ STAR was designed with the intention to store publications in a manner most useful to researchers. As a first step, possible types of research reports were categorized into three categories: peer-reviewed articles, dissertation and theses, and grey literature. Grey literature is a widely-used term referring to professional conference contributions, transcripts or videos of invited keynote presentations and plenary talks, meeting proceedings, books and book chapters on astronomy teaching excellence, and Internet blog posts, as well as seminar and workshop presentations (viz., Slater, 2015; 2016). Even though not often rigorously peer-reviewed, it is our belief that highly insightful and valuable information for astronomy education researchers, when explicitly labeled as such, is also contained in the domain of grey literature. As an example of grey literature scholarship, the Appendix provided lists some of the grey literature scholarship leading up to publication of this article.

The following categories were developed to create an initial scheme that would be most helpful to researchers in the field, and facilitate searches for relevant works pertaining to any research topic of choice. Those categories were sent out to 15 international experts in astronomy education for review and comment. Definitions were then written for each of the header and sub-categories to set the boundaries for how items would be classified. This new draft was also sent out to 15 international experts in the astronomy education field for comments and suggestions. The experts came from a variety of countries including Australia, Brazil, Japan, Denmark, Portugal, Spain, South Africa and the United States. This panel of experts helped redefine and edit the categories. Table 2 shows the developed $i$ STAR categorization scheme and their definitions. 
Table 2. Categories for Reviewing Astronomy Education Research Reports

\begin{tabular}{|c|c|}
\hline Category & Definition \\
\hline \multicolumn{2}{|l|}{ Document Source } \\
\hline Peer-reviewed & $\begin{array}{l}\text { Published academic or scientific work judged as valuable, timely, and rigorous by other } \\
\text { scholars in the field }\end{array}$ \\
\hline Dissertation or Thesis & $\begin{array}{l}\text { A paper that is used to fulfill the requirement of a higher educational degree, juried by } \\
\text { university faculty }\end{array}$ \\
\hline Grey literature & $\begin{array}{l}\text { Research presented at conferences, on websites, in newsletters produced by organizations } \\
\text { or societies but not through commercial channels, e.g., pre-prints, conference } \\
\text { proceedings, statistical reports, preliminary progress reports }\end{array}$ \\
\hline \multicolumn{2}{|r|}{, } \\
\hline Literature review & $\begin{array}{l}\text { A comprehensive comparison and contrast paper which critically summarizes or } \\
\text { synthesizes the current knowledge across an academic landscape }\end{array}$ \\
\hline Empirical research & A scientific study conducted using data collected via observation or experiment \\
\hline Theoretical research & $\begin{array}{l}\text { A study describing a pre-existing, redefined, or new theory that makes a priori predictions } \\
\text { about proposed experiments }\end{array}$ \\
\hline Curriculum or program evaluation & An assessment on the effectiveness of an education program or curriculum design \\
\hline Curriculum description or report & A paper describing and documenting an educational program or curriculum design \\
\hline Position paper or editorial & A non-refereed opinion-oriented publication \\
\hline Historical & A paper describing past events and its influence today \\
\hline Bibliography or resource guide & $\begin{array}{l}\text { A summary of the literature or annotated guide to existing literature or educational } \\
\text { resources }\end{array}$ \\
\hline \multicolumn{2}{|l|}{ Empirical Methodology } \\
\hline Quantitative & $\begin{array}{l}\text { Research designed to quantify an educational state, or change of state, by transforming } \\
\text { observations into numerical data that can be statistically analyzed }\end{array}$ \\
\hline Qualitative \& Interpretive & $\begin{array}{l}\text { Research designed to explore underlying causal mechanisms occurring and meaning- } \\
\text { making participants experience interpreted without extensive use of traditional statistical } \\
\text { analysis }\end{array}$ \\
\hline Mixed-methods & $\begin{array}{l}\text { A study using both qualitative and quantitative methods to triangulate an evidence based } \\
\text { conclusion from multiple philosophical perspectives and viewpoints }\end{array}$ \\
\hline \multicolumn{2}{|l|}{ Learning Environment } \\
\hline Formal & $\begin{array}{l}\text { Context is school-like classroom setting, led by trained instructors, with specified and } \\
\text { assessed learning targets }\end{array}$ \\
\hline Informal & $\begin{array}{l}\text { A study conducted outside of a classroom setting (e.g., after-school programs, museums, } \\
\text { star parties, field trips, etc.) }\end{array}$ \\
\hline \multicolumn{2}{|l|}{ Research Setting } \\
\hline Planetarium & Any study incorporating the use of a physical planetarium \\
\hline Museum & Science learning center or facility that preserves historical artifacts \\
\hline Amateur Groups or Activities & $\begin{array}{l}\text { A study involving non-professional (e.g., star parties, variable star data collected via } \\
\text { amateur astronomers, etc.) }\end{array}$ \\
\hline $\begin{array}{l}\text { Extracurricular/Camps/After- } \\
\text { school/Scouting }\end{array}$ & Non-school related educational activities that are rarely graded \\
\hline Home school & Students who do not attend a traditional brick-and-mortar school building \\
\hline Online, virtual & $\begin{array}{l}\text { Students who do not attend a traditional brick-and-mortar school building and take } \\
\text { synchronous or asynchronous classes via an Internet connection }\end{array}$ \\
\hline Citizen science & $\begin{array}{l}\text { Individuals who are not paid professional scientists who are contributing to scientific data } \\
\text { collection or analysis }\end{array}$ \\
\hline Research facility & $\begin{array}{l}\text { National laboratory or scientific research institution that is not a college, university, or } \\
\text { museum }\end{array}$ \\
\hline
\end{tabular}


(Table 2 continued)

\begin{tabular}{|c|c|}
\hline Category & Definition \\
\hline \multicolumn{2}{|l|}{ Study Participants } \\
\hline Early childhood students & Younger than 5 years of age \\
\hline Elementary students & Students ages $5-11$ years of age \\
\hline Middle \& secondary school students & Students ages $11-18$ years of age \\
\hline College students & Students enrolled in an undergraduate course \\
\hline Second language learners & Students enrolled in a course or school not taught in their first language learned \\
\hline Graduate students & Students pursuing higher education degrees such as a doctorate or masters \\
\hline Pre-service teachers & College students pursuing a career as a teacher \\
\hline In-service Teachers & Teachers currently educating students ages $3-18$ years old \\
\hline College faculty & Participants teaching at a higher education institution \\
\hline Multi-aged groups & Family or community groups with varying ages \\
\hline Adult learners & Retirees or third-age learners (e.g., Elderhostel) \\
\hline \multicolumn{2}{|l|}{ Construct } \\
\hline Content knowledge & Facts, concepts, theories, etc. \\
\hline Affective variables & Belief, identity, motivation, attitudes, etc. \\
\hline Cognitive processes & Attention, memory, working memory, judgment, reasoning, etc. \\
\hline Quantitative reasoning & Ability to read and understand mathematical problems \\
\hline Spatial reasoning & The capacity to visualize and manipulate mental images \\
\hline Research \& methods assessment & The research methodologies used in empirical and evaluation studies \\
\hline General teaching strategies & The didactic, pedagogical, praxis, and educational engagement process \\
\hline Scientific inquiry & The processes involved in developing scientific knowledge \\
\hline Nature of Science & The understanding of science as a way of knowing \\
\hline \multicolumn{2}{|c|}{ Scientific Content Focus Area } \\
\hline \multicolumn{2}{|c|}{ General/Broad Knowledge of Astronomy Content } \\
\hline \multicolumn{2}{|c|}{ Stars } \\
\hline \multicolumn{2}{|l|}{ Sun-Earth-Moon } \\
\hline \multicolumn{2}{|l|}{ Solar System } \\
\hline \multicolumn{2}{|l|}{ Scale \& Structure } \\
\hline \multicolumn{2}{|l|}{ Cosmology } \\
\hline \multicolumn{2}{|l|}{ Atoms \& Light } \\
\hline \multicolumn{2}{|l|}{ History of Astronomy } \\
\hline \multicolumn{2}{|l|}{ Astrobiology \& Exoplanets } \\
\hline \multicolumn{2}{|l|}{ Galaxies } \\
\hline \multicolumn{2}{|l|}{ Gravity } \\
\hline \multicolumn{2}{|l|}{ Cultural Astronomy } \\
\hline \multicolumn{2}{|l|}{ Other } \\
\hline \multicolumn{2}{|l|}{ Demographic Focus } \\
\hline \multicolumn{2}{|l|}{ Multicultural or indigenous } \\
\hline \multicolumn{2}{|l|}{ Gender \& sex differences } \\
\hline \multicolumn{2}{|l|}{ Disability } \\
\hline \multicolumn{2}{|l|}{ Gifted } \\
\hline \multicolumn{2}{|l|}{ Low socio-economic status } \\
\hline \multicolumn{2}{|l|}{ Other } \\
\hline Language of Publication & \\
\hline Paper written in English & \\
\hline Abstract only in English & \\
\hline Non-English publication & \\
\hline Location Study Conducted & \\
\hline USA & \\
\hline Other & \\
\hline
\end{tabular}




\section{Graphical User Interface Design}

To meet the goal of making scholarly astronomy education research works as easy to survey and analyze as possible, an Internet-accessible search form was designed by the authors and their colleagues. The underlying programing system was designed by Open Repository in the United Kingdom, who designed the database using an open source DSpace protocol. Initial seed funding was provided by the CAPER Center for Astronomy \& Physics Education Research in the U.S., and by Open Repository who use their resources to support scholarly efforts that increase equitable access across international settings.

The $i$ STAR database search pages are intentionally created to be easy to use for international scholars with limited English proficiency. For the $i$ STAR database to withstand the vagaries of unstable funding, astronomy education research community members themselves can add files and categorize their own uploads. Each of the works submitted to the database can be vetted through a moderated "workflow" process, where approved administrators can either accept/reject the items, or edit the categorizations. There are no restrictions for access.

\section{FINDINGS}

This surprisingly large initial sample of scholarly work glimpsed through this first light survey of astronomy education research dissertations is analyzed using descriptive statistics. Further inferential analyses will be the subject of subsequent papers. The tables and plots provided in this section illustrate the power of the iSTAR database by describing the number of works generated per year, the number of works per institution, dominant type of research methods employed, learning environments studied, characteristics of study-participants surveyed, definitions and constructs framing the work, and the scientific content domains under study.

\section{Year of Dissertation or Thesis Completion}

Table 3 provides the frequency count of papers in the United States in the existing $i$ STAR database in five year bins over the 89-year span of the database, as of this writing. It is important to note that this dataset is incomplete and most certainly does not yet exhaustively represent the full history of the field. In building the database, more recent works are often far more accessible via online databases, both in terms of finding the title and author of a paper, and in terms of being able to acquire a digital copy of the work. In particular, many known works dating from the 1960s, 1970s and 1980s have never been digitized, and are not available through traditional interlibrary loan programs because there is only one paper hardcopy. Therefore, any inference from the current dataset that the field of astronomy education research has been more productive in the most recent years is unsupported; instead, it stands as witness to the notion that much of our research heritage has been heretofore largely unavailable to many scholars.

Table 3. Distribution of 252 Initially Recovered Graduate Dissertations and Theses across Bands of Time

\begin{tabular}{c|c|c|c}
\hline Years & Number of works & Years & Number of works \\
\hline $1925-1929$ & 1 & $1975-1979$ & 9 \\
\hline $1930-1934$ & 2 & $1980-1984$ & 12 \\
\hline $1935-1939$ & 0 & $1985-1989$ & 13 \\
\hline $1940-1944$ & 1 & $1990-1994$ & 22 \\
\hline $1945-1949$ & 3 & $1995-1999$ & 25 \\
\hline $1950-1954$ & 0 & $2000-2004$ & 25 \\
\hline $1955-1959$ & 2 & $2005-2009$ & 48 \\
\hline $1960-1964$ & 6 & $2010-2014$ & 61 \\
\hline $1965-1969$ & 10 & 2015 & 3 \\
\hline $1970-1974$ & 9 & & \\
\hline
\end{tabular}

\section{Institutions Supporting Astronomy Education Degree Work}

Table 4 provides a frequency count of dissertations and theses per institution for those institutions producing more than four degrees, as cataloged in the database as of this writing. In total, 101 post-secondary institutions of higher 
education (colleges and universities) contributed to this body of work, with ten institutions producing nearly a third of all degrees in the dataset. It is worth noting that work produced in these high-production institutions is concentrated within relatively short periods of time. For example, the University of Southern California dominated scholarly production in astronomy education research in the 1930s and 1940s then suddenly ceased. In the case of Oklahoma State University, top production of degrees occurred in the 1990s under the supervision of a group of faculty who have since moved to other institutions or have retired. As another example, Montana State University's productivity dramatically increased in the 2010s with the publication of theses resulting from a new Master's of Science degree in Interdisciplinary Science Education program.

Whereas sometimes particular universities become dominant producers of scholarly work because of its degree programs, other universities become dominant producers because of particular individuals. This is particularly true in AER, where no formal departments exist, and production is driven by the presence a single scholar at an institution. For example, production of astronomy education dissertations and theses at The Ohio State University peaked in the 2000s, abruptly ending with the departure of Dr. Kathy Trundle, who left that institution to become the department chair for Science, Technology, Engineering, and Mathematics (STEM) education at North Carolina State University. Peak scholarly production at the University of Arizona occurred during the 2000s and sharply declined after the departure of Professor Timothy Slater who went on to an endowed professorship at the University of Wyoming. The University of Wyoming's graduate theses and dissertation production skyrocketed starting in 2010. This pattern should be expected to continue. For example, while Penn State does not currently appear on the list of top institutional producers, we might expect that Penn State will see a dramatic increase in productivity in this area with the arrival of planetarium education scholar, Dr. Julia Plummer.

Table 4. Institutions Producing the Largest Number of Astronomy Education Dissertations and Theses as of 2015

\begin{tabular}{l|c}
\hline \multicolumn{1}{c|}{ Institution } & Number of degrees produced \\
\hline University of Arizona & 16 \\
\hline Montana State University & 14 \\
\hline University of Southern California & 11 \\
\hline The Ohio State University & 8 \\
\hline Oklahoma State University & 7 \\
\hline University of Wyoming & 7 \\
\hline Columbia University & 6 \\
\hline Temple University & 6 \\
\hline University of Iowa & 6 \\
\hline University of Michigan & 6 \\
\hline
\end{tabular}

As emphasized in the previous section, this initial "first light" sample is certainly incomplete, but provides a unique glimpse into the demographics of astronomy education research conducted in partial fulfillment of graduate degrees earned in the United States.

\section{Dissertation or Graduate Thesis Research Methods}

Within the $i$ STAR database, all complete entries for empirical works entered to date are categorized as quantitative, qualitative or mixed-method studies. Whenever possible this classification was determined through the abstract's explicit statements. When the work did not explicitly declare its research method, a determination was made by the coder, often by carefully reading the methods section of the work. While quantitative works tend to be relatively easy to classify quickly, classification for qualitative and mixed-method works can be more open to interpretation. Prior to the 1980s, it was common to characterize research as qualitative if it involved data that began analysis in nonnumerical form, was later quantified, and statistically analyzed: Today, such a study would be described instead as quantitative even if the data was initially non-numeric in form if it is eventually reported in terms of frequency counts. The period between 1980 and 2000 is known by many across the discipline-based education research community as the time of the "paradigm wars" (Gage, 1989). During that period, community-wide battles for an expansion of the accepted research methods and methodologies raged, resulting in a research community in which non-experimental and non-quantitative methods were increasingly accepted as legitimate research practices. During the paradigm wars Copyright by author(s); $\underline{\text { CC-BY }}$ 
and since, qualitative research tends to be, but is not always defined as, research that has as its focus the contextually significant experience of the participants (Erickson, 1986), a perspective which would frequently exclude papers designated as qualitative work prior to the paradigm wars. A determination of "mixed methods" could therefore mean a variety of things, depending upon the era and the perspective of the author. For the purposes of the coders of the initial sample loaded into iSTAR, the coding scheme used is largely based on Niglas' (2000) work. Having said that, the categorization of works using this scheme is imprecise and others may occasionally disagree with the selfcategorization completed by the authors themselves.

Nonetheless, the initial data set in the iSTAR database that included both an abstract and a narrative body judged to be closely related to astronomy education were categorized as using quantitative $(\mathrm{n}=105)$, qualitative $(\mathrm{n}=58)$, or mixed methods $(\mathrm{n}=56)$. More interestingly, the proportion of research methods employed has evolved over time. The data were disaggregated into three domains: pre-paradigm wars (1927-1980), paradigm wars (1981-2000), and postparadigm wars (2001-2015). During all periods, quantitative research methods dominate and qualitative and mixed methods increase as shown in Table 5.

Table 5. Distribution of Research Methods Used by Research Era

\begin{tabular}{l|c|c|c}
\hline & $\mathbf{1 9 2 7 - 1 9 8 0}$ & $\mathbf{1 9 8 1 - 2 0 0 0}$ & $\mathbf{2 0 0 1 - 2 0 1 5}$ \\
\hline Quantitative & $76 \%$ & $52 \%$ & $37 \%$ \\
\hline Qualitative & $5 \%$ & $29 \%$ & $32 \%$ \\
\hline Mixed Methods & $18 \%$ & $19 \%$ & $31 \%$ \\
\hline
\end{tabular}

Data were also examined to see if there are any institutional trends at those institutions that produce the greatest number of works. While the numbers are small, there does seem to be a research "preference" at three of the top producers. The University of Arizona and The Ohio State University showed a tendency towards qualitative and mixed methodologies during their periods of productivity ( 12 out of 16 works, and 7 out of 8 works, respectively). In contrast, Montana State University exhibited an obvious research preference toward quantitative methodologies (10 out of 14 works). Other frequent producers showed no meaningful tendencies one way or the other.

\section{Beyond Classroom Research Settings}

Table 6 provides the frequency of works in the database that were specifically conducted outside of classrooms-like settings $(\mathrm{n}=77)$. While the eventual inclusion of not-immediately-available, non-digitized works from the frenzied planetarium-building construction phase of the 1950s and 60s will likely increase the number of categorized works conducted in non-formal out-of-school type settings, it is unlikely to shift the general trend: graduate theses and dissertations about planetarium learning environments represent the clear majority of works $(n=54,70 \%)$.

Table 6. 77 Dissertation \& Graduate Theses Listed by Informal Research Setting

\begin{tabular}{l|c}
\hline \multicolumn{1}{c}{ Research Setting } & Number of works \\
\hline Planetarium & 54 \\
\hline Extracurricular/Camps/After-school & 4 \\
\hline Online/Virtual & 4 \\
\hline Museum & 3 \\
\hline Research Experiences & 2 \\
\hline Amateur Groups & 2 \\
\hline Citizen Science & 2 \\
\hline Indigenous Site & 1 \\
\hline Music & 1 \\
\hline Observatory & 1 \\
\hline Research Facility & 1 \\
\hline Sacred Mountains & 1 \\
\hline Star Party & 1 \\
\hline
\end{tabular}




\section{Subjects and Participants Studied}

The $i$ STAR database allows users to investigate the characteristics of the study-participants, allowing for multiple selections per work. Thirty-one dissertations and theses in the sample did not actually involve human subjects. These works performed curriculum studies, historical analyses, and descriptions of planetarium program or facility development. The remaining dissertations and theses described characteristics of 236 different participant groups. Studies of middle and secondary students $(n=71,30.1 \%)$ and college students $(n=58,24.6 \%)$ make up more than half of the participants involved, as shown in Table 7.

Table 7. Frequency of Participant Group Categories in 236 Dissertations and Graduate Theses

\begin{tabular}{l|c|c}
\hline \multicolumn{1}{c}{ Participants } & Works & Percentage of all works \\
\hline Middle/High Sch. Students & 71 & $30.1 \%$ \\
\hline College Students & 58 & $24.6 \%$ \\
\hline Elementary Sch. Students & 35 & $14.8 \%$ \\
\hline Practicing Teachers & 29 & $12.3 \%$ \\
\hline Multi-aged Groups & 13 & $5.5 \%$ \\
\hline Future Teachers & 11 & $4.7 \%$ \\
\hline College Faculty & 6 & $2.5 \%$ \\
\hline Adult Learners & 4 & $1.7 \%$ \\
\hline Graduate Students & 2 & $0.8 \%$ \\
\hline Scientists & 2 & $0.8 \%$ \\
\hline Families & 1 & $0.4 \%$ \\
\hline Pre-primary Students & 1 & $0.4 \%$ \\
\hline Staff & 1 & $0.4 \%$ \\
\hline Indigenous Peoples & 1 & $0.4 \%$ \\
\hline Parents & 1 & $0.4 \%$ \\
\hline
\end{tabular}

With regard to the specific demographic groups in which education researchers are interested, these evolve over time. Data were disaggregated to determine any trends that could be observed. Percentages were calculated to determine the types of subjects (i.e., adults, older children, and younger children) studied in each of the research eras described in the previous section. The number of studies categorized for the early eras is relatively small ( $\mathrm{n}=29)$, which may influence the trend observed. However, it appears that the number of studies involving young children have declined, while those involving adults, particularly in-service and pre-service teachers, have increased. Studies involving older school children in middle and high school have remained steady, and are shown in Table 8. It is possible that the observed trend reflects a general shift in the focus in astronomy education. Alternatively, this trend may be a natural research community response to the development of more stringent Human Subjects Protections in the mid-1970s, (Slater, Slater, Heyer, \& Bailey, 2015, p. 118; H.H.S., n.d., para. 6) and its increasing impact in the social sciences. It is possible that the growing difficulty in conducting research involving minor-aged school children is a barrier to such studies being conducted at the graduate school level. A similar analysis involving works completed by faculty rather than graduate students may provide additional insight.

Table 8. Distribution of Participant Groups Studied by Research Era

\begin{tabular}{l|c|l|c}
\hline \multicolumn{1}{c|}{ Age Group } & $\begin{array}{c}\text { Research Era } \\
\mathbf{1 9 2 7 - 1 9 8 0}\end{array}$ & \multicolumn{1}{c}{ Age Group } & $\begin{array}{c}\text { Research Era } \\
\mathbf{1 9 2 7 - 1 9 8 0}\end{array}$ \\
\hline Adults & $40 \%$ & Adults & $40 \%$ \\
\hline Older Children & $40 \%$ & Older Children & $40 \%$ \\
\hline
\end{tabular}

\section{Research Constructs Framing the Studies}

Traditionally, the "research construct" is the proposed attribute that often cannot be measured directly, but can potentially be assessed using a number of proxy indicators or assessments (Cronbach \& Meehl, 1955; Messick, 1995). In astronomy education research, we are often interested in measuring school children's' conceptual or content 
knowledge levels, the depth of understanding of the nature of science, and their attitude or affect toward science. When we study adults - teachers, faculty and scientists - we are still interested in these constructs, and we might also be interested in their general teaching ability, or their spatial reasoning skills. In the $i$ STAR database, entries are coded for the construct(s) studied - a given work may involve more than one construct of interest. The 236 publications that could be sensibly categorized for "construct" produced 373 construct codings. It is perhaps unsurprising to most scholars that the two most studied constructs in the sample are content knowledge $(\mathrm{n}=129,35 \%)$ and affect $(\mathrm{n}=77$, $21 \%$ ). It should be noted that the "affect" category is a mixture of interest, value, attitude/belief, and identity, as the ways in which those terms have been used over the decades is often interwoven, overlapping, and difficult to parse out. These are illustrated in Table 9 and in Figure 6.

Table 9. Frequency of Constructs Studied in 236 Dissertations and Graduate Theses

\begin{tabular}{l|c|c}
\hline \multicolumn{1}{c}{ Construct } & Number of Codings & Percentage of Codings \\
\hline Content Knowledge & 129 & $35 \%$ \\
\hline Affective Belief/Identity Motivation/Attitude & 77 & $21 \%$ \\
\hline General Teaching Strategies & 70 & $19 \%$ \\
\hline Spatial Reasoning & 26 & $6 \%$ \\
\hline Cognitive Processes & 22 & $5 \%$ \\
\hline Nature of Science & 18 & $4 \%$ \\
\hline Scientific Inquiry & 15 & $2 \%$ \\
\hline Quantitative Reasoning & 7 & $1 \%$ \\
\hline Communication Skills & 2 & $1 \%$ \\
\hline Research Methods/Assessment & 2 & $1 \%$ \\
\hline Technology Use & 4 & \\
\hline
\end{tabular}

\section{Astronomy Content Knowledge Studied}

Of the 145 works that could be categorized in this way, Table 10 provides the frequency of domains of astronomical content knowledge studied. In an effort to achieve some type of coherence, content areas were collapsed whenever possible. For instance, if a dissertation was studying students' understanding of the H-R Diagram, it was categorized as focusing on the broader category of "stars," even though that larger category naturally misses some of the nuance of the work. Over the 89 years of astronomy education research works sampled for this paper, "General Knowledge/Vocabulary" has, by a wide margin, been the most common topic studied ( $\mathrm{n}=52,36 \%)$. The "Sun-EarthMoon" system, which includes the topics of lunar phases and seasons was a common second choice ( $\mathrm{n}=32,22 \%)$.

Table 10. Frequency of Content Areas Studied in 145 Dissertations and Graduate Theses

\begin{tabular}{l|cc}
\hline \multicolumn{1}{c|}{ Content } & Number of Works & Percentage of Categorized Works \\
\hline General Knowledge \& Vocabulary & 52 & $36 \%$ \\
\hline Sun-Earth-Moon & 32 & $22 \%$ \\
\hline Stars & 13 & $9 \%$ \\
\hline Celestial Motion \& Navigation & 8 & $6 \%$ \\
\hline Solar System & 7 & $5 \%$ \\
\hline Cosmology & 6 & $4 \%$ \\
\hline Scale \& Structure & 6 & $3 \%$ \\
\hline Atoms \& Light & 4 & $2 \%$ \\
\hline Gravity & 3 & $1 \%$ \\
\hline Music \& Art & 2 & $1 \%$ \\
\hline Night sky \& Constellations & 2 & $1 \%$ \\
\hline Telescopes \& Optics & 2 & $1 \%$ \\
\hline Astrobiology \& Exoplanets & 2 & \\
\hline
\end{tabular}

Given that other portions of the categorization scheme currently demonstrate trends over time, the category related to content was also analyzed for trends over time. While "General Knowledge" is most studied content area over all three 
research eras, it has decreased in prevalence. In the 1927-1980 period, "General Knowledge" accounted for $60 \%$ $(n=15)$ of all categorized studies, decreasing to $40 \%(n=17)$ in the period between 1980 and 2000 , and to $26 \%$ in the period since $2000(\mathrm{n}=20)$. While "Sun-Earth-Moon" has remained relatively stable in frequency, other topics appear in good numbers in the period since 2000, including cosmology, scale and structure, and Solar System. Nonetheless, one would not expect "General Knowledge" to disappear, as it is the content area most often engaged when studies focus on constructs such as "Nature of Science," "Scientific Inquiry," "Teaching Strategies," and "Spatial Reasoning." As researchers more aggressively venture into these domains, the data might show an increase in the number of "General Knowledge" content studies.

\section{DISCUSSION}

In this first light analysis paper, we found that there have been at least three times as many dissertations and graduate theses produced in AER than expected, and that these works were being completed far earlier in AER's history than we imagined. These scholarly works display an extraordinary range of theoretical frameworks and methods, as demonstrated statistically. By and large, we judge the majority of these works to be rigorous and robust; in some cases, we judge the works to be quite brilliant and insightful, although we had never heard of the papers or their authors previously. Further, most AER topics one might wish to investigate have been touched on by one of these largely unknown scholarly treasures. Indeed, we found that many of our own ideas related to research questions for future projects had already been thought of before, by researchers perhaps decades ago. This certainly does not mean that we should not pursue answers to our questions; rather, if our field is to make progress, we must pursue those questions, building upon the findings of previous studies.

These works have much to teach us, yet prior to insertion in the $i$ STAR repository most of these studies were not previously available in digital format, or in many instances, outside of the walls of their home libraries. We can only wonder how many more useful existing works are hidden in the shelves of libraries across the planet, or in the pages of journals unknown to us. If this sample reflects the greater problem of dispersed research, it is safe to assert that the number of "hidden works" is quite large.

We must collect these works. Until the field can accomplish that task, there is no process by which we can organize and begin to digest the whole of what we know about human thinking as it relates to astronomy. Without such a comprehensive organization of knowledge, it would be reasonable to say that astronomy education research has been a "pre-watershed" endeavor, with activity tending to be disparate, and perhaps a bit haphazard. According to Illich (1973), professional endeavors experience watershed moments when practitioners begin to ask questions which require them to reconsider their beliefs, seek out novel sources of information, and reorganize the collective knowledge into new coordinating theories

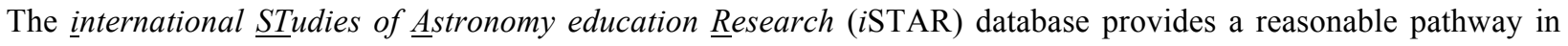
which scholars may come to know, value, and build upon the work of a larger base of researchers, from a variety of countries, in order to support wider AER research collaborations. By building a database in which scholarly works from the larger international community can be highlighted, iSTAR seeks to bring a more equitable balance to the recognition and subsequent influence of works from a broader international base of researchers while fostering a more collaborative international research environment. Such a watershed moment in AER would have the potential to facilitate collaborations and to enhance their effectiveness. Research may become more rigorous based upon an expanded library of tested research approaches. Research may also become more meaningful, drawing upon a broader conception of the ways that a wider diversity of humans can interact with the content and processes of astronomy. The $i$ STAR online repository, with its growing and evolving representation of the various products of research enterprises around the world, is one pathway toward that first watershed in AER.

With the iSTAR repository as a structure upon which to move forward, we call for a new level of international and cross-disciplinary collaboration and coordination to better target key questions within the domain of AER. We encourage the submission of a wide variety of AER publications to the repository from all relevant parties; the use of $i \mathrm{STAR}$ as a means to organize our collective works; and the creation of vastly expanded reviews of the literature leading to new theoretical conceptions and methods in the field of astronomy education research. 


\section{ACKNOWLEDGMENTS}

We gratefully acknowledge initial funding for the istardatabase.org website from Open Repository, the CAPER Center for Astronomy \& Physics Education Research, and the Wyoming Endowment for Excellence in Higher Education.

\section{AUTHOR BIOGRAPHIES}

Stephanie Slater is the Director of the CAPER Center for Astronomy \& Physics Education Research, which funded initial development of the $i$ STAR database, and a recognized scholar in discipline-based astronomy education research. Correspondence about this project should be directed to her at Email: stephanie@caperteam.com

Coty Tatge has been working on a Ph.D. in Science Education University of Wyoming and has been helping to build an international database of astronomy education research materials for scholars to use in characterizing the landscape of astronomy education research.

Paulo Bretones is the Chair of the International Astronomical Union's Working Group on Astronomy Education and an Adjunct Professor at the São Carlos Federal University UFSCar.

Tim Slater holds the University of Wyoming Excellence in Higher Education Endowed Chair of Science Education where he is appointed to the rank of Professor.

Sharon Schleigh is an Assistant Professor of Science Education at East Carolina University where she is the Assistant Director of the East Carolina Space Grant Collaborative.

David McKinnon is a Professor of Education at Edith Cowan University and the Director of the Edith Cowan Institute for Education Research in Perth, Western Australia.

Inge Heyer is a Visiting Assistant Professor of Physics at Loyola University Maryland, where she teaches physics, astronomy, and integrated science for elementary education majors.

\section{REFERENCES}

Adams, J. P., \& Slater, T. F. (2000). Astronomy in the National Science Education Standards. Journal of Geoscience Education, $48(1), 39-45$.

Bailey, J. M., \& Slater, T. F. (2003). A review of astronomy education research. Astronomy Education Review, $2(2), 20-45$.

Brazell, B. D., \& Espinoza, S. (2009). Meta-analysis of planetarium efficacy research. Astronomy Education Review, 8(1).

Bretones, P. S., Jafelice, L. C., \& Horvath, J. E. (2016). Ten years of RELEA: Achievements and challenges for astronomy education development. Journal of Astronomy \& Earth Sciences Education, 3(2).

Bretones, P. S., \& Megid Neto, J. (2011). An analysis of papers on astronomy education in proceedings of IAU meetings from 1988 to 2006. Astronomy Education Review, 10(1), 10-18.

Broadfoot, J. M., \& Ginns, I. S. (2005). Astronomy education research down under. In Effective Strategies for Educators Worldwide, Pasachoff, J. M., \& Percy, J. R., eds. New York: Cambridge.

Cronbach, L. J., \& Meehl, P. E. (1955). Construct validity in psychological tests. Psychological bulletin, $52(4), 281$.

Erickson, F. (1986). Qualitative methods in research on teaching. In M. C. Wittrock (Ed.), Handbook of research on teaching (3rd ed.) (pp. 119-161). New York: Macmillan.

Fraknoi, A. (2014). A brief history of publishing papers on astronomy education research. Journal of Astronomy \& Earth Sciences Education, 1(1), 37-40.

Fraknoi, A., \& Wolff, S. (2007). Astronomy education review: A five-year progress report and thoughts about the journal's future. Astronomy Education Review, 5(2), 1-4.

Gage, N.L. (1989). The paradigm wars and their aftermath: a "historical" sketch of research on teaching since 1989. Educational Researcher, 18(7), 4-10.

H.H.S. (n.d.). Information on Protection of Human Subjects in Research Funded or Regulated by U.S. Government. U.S. Department of Health \& Human Services, retrieved from: http:/www.hhs.gov/1946inoculationstudy/protection.html

Illich, I. (1973). Re-Tooling society. Philippine Studies, 21(1/2), 125-185.

Lelliott, A., \& Rollnick, M. (2010). Big ideas: A review of astronomy education research 1974-2008. International Journal of Science Education, 32(13), 1771-1799.

Copyright by author(s); $\underline{\text { CC-BY }}$ 
Messick, S. (1995). Validity of psychological assessment: validation of inferences from persons' responses and performances as scientific inquiry into score meaning. American Psychologist, 50(9), 741.

Niglas, K. (2000, September). Quantitative and qualitative inquiry in educational research: Is there a paradigmatic difference between them? Paper presented at the European Conference on Educational Research, Lahti, Finland.

Ralya, L. L., \& Ralya, L. L. (1940). Some significant concepts and beliefs in astronomy and geology of entering college freshmen and the relation of these to general scholastic aptitude. School Science and Mathematics, 40(8), 727-734.

Slater, S. J. (2014). The development and validation of the Test $\underline{\text { Of }}$ Astronomy STandards (TOAST). Journal of Astronomy \& Earth Sciences Education, 1(1), 1-22.

Slater, S. J., Slater, T. F., Heyer, I., \& Bailey, J. M. (2015). Conducting astronomy education research: an astronomer's guide, 2nd edition. Hilo, Hawai'i: Pono Publishing. ISBN: 1515025322.

Slater, T. F. (2015). Is the best astronomy education research 'grey'? Retrieved from AstroLrner.org Blog at https://astronomyfacultylounge.wordpress.com/2015/09/24/is-the-best-astronomy-education-research-grey/

Slater, T. F. (2016). Undiscovered value of grey astronomy education research results. The Grey Journal, 12(3), 153-155

Wall, C. A. (1973). A review of research related to astronomy education. School Science and Mathematics, 73(8), 653-669. 


\section{APPENDIX}

\section{Sample of "Grey Literature" Scholarship Preceding iSTAR Database Initial Release}

1. Bretones, P. S., \& Megid Neto, J. (2005). Tendências de teses e dissertações sobre educação em astronomia no Brasil. Boletim da Sociedade Astronômica Brasileira, 24(2), 35-43.

2. Bretones, P. S., Megid Neto, J., \& Canalle, J. B. G. (2006). A educação em astronomia nos trabalhos das reuniões anuais da Sociedade Astronômica Brasileira. Boletim da Sociedade Astronômica Brasileira, 26(2), 5572.

3. Bretones, P. S. (2011). Banco de teses e dissertações sobre educação em astronomia: implantação, dificuldades e possíveis contribuições. Simpósio Nacional de Educação em Astronomia, I, 2011, Rio de Janeiro, Atas... Rio de Janeiro.

4. Ortelan, G. B., \& Bretones, P. S. (2012). Educação em astronomia nos trabalhos das reuniões anuais da SAB entre 2004 e 2010. Reunião Anual Da Sociedade Astronômica Brasileira, 37, in, Águas de Lindóia. Atas... Águas de Lindóia, 2012. p. 76.

5. Bretones, P. S. (2012). Banco de teses e dissertações sobre educação em astronomia: implantação, dificuldades e possíveis contribuições. 2011. Simpósio Nacional De Educação Em Astronomia, 1, 2011, Rio de Janeiro. Atas... São Paulo: SAB, 2012.

6. Retrieved from: http://snea2011.vitis.uspnet.usp.br/sites/default/files/SNEA2011_TCO15.pdf

7. Bussi, B., \& Bretones, P. S. (2013). Educação em astronomia nos trabalhos dos ENPECs de 1997 a 2011. Encontro Nacional de Pesquisa em Educação em Ciências, 9, in, Águas de Lindóia. Atas... Rio de Janeiro; ABRAPEC.

8. Slater, S. J., Bretones, P. S., McKinnon, D., Schleigh, S. P., \& Slater, T. F. (2013). Crafting an international study of students' conceptual understanding of astronomy. American Astronomical Society Meeting Abstracts, 221.

9. Slater, S. J., \& Tatge, C. B. (2015). Design of the iSTAR international STudy of Astronomy Reasoning. American Astronomical Society Meeting Abstracts, 225.

10. Slater, S. J., Tatge, C. B., Slater, T. F., Schleigh, S. P., \& Bretones, P. S. (2016). Overview of U.S. Astronomy Education Research dissertations in the $i$ STAR Database. Presentation at the American Association of Physics Teachers Meeting in Sacramento, July, 2016.

11. Slater, T. F., \& Slater, S. J. (2011). Multi-institutional collaborative astronomy education research. Proceedings of Astronomical Society of the Pacific's Earth and Space Science: Making Connections in Education and Public Outreach conference held at the University of Colorado, Boulder, Colorado, USA 31 July 31 - August 4 2010. Edited by Joseph B. Jensen, James G. Manning, and Michael G. Gibbs. San Francisco: Astronomical Society of the Pacific, 2011, p.363.

12. Slater, T. F., Tatge, C. B., Slater, S.J., Schleigh, S. P., Bretones, P. S., \& McKinnon, D. (2016). Expanding the Reach of the $i$ STAR international STudy of Astronomical Reasoning. Proceedings of the International Science Education Conference, Venice, Italy, June 6, 2016.

13. Slater, T. F. (2017). New lessons from the last 200 planetarium education research dissertations. Invited presentation to the American Association of Physics Teachers conference, Atlanta, GA, February 19, 2017.

14. Tatge, C. B., Slater, S. J., \& Slater, T. F. (2014). Improving astronomy education in the United States by investigating other cultures. Proceedings of the National Symposium in Astronomy Education, Curitiba, Brazil.

15. Tatge, C. B., Slater, S. J., \& Slater, T. F. (2015). First Results from the $i$ STAR international STudy of Astronomy Reasoning. American Astronomical Society Meeting Abstracts, 225.

16. Tatge, C. B., Slater, T. F., \& Slater, S. J. (2015). iSTAR: The international STudy of Astronomy Reasoning. Presentation at the International Astronomical Union General Assembly, Honolulu, HI, 22, 57436.

17. Tatge, C. B., Slater, S., Slater, T. F., Bretones, P. S., McKinnon, D., \& Schleigh, S. P. (2016). First Light Observations from the international STudy of Astronomy Reasoning (iSTAR) Database. American Astronomical Society Meeting Abstracts, 227.

18. Tatge, C. B., Slater, S. J., \& Slater, T. F. (2016). Analysis and characterization of planetarium education research in the $i$ STAR international STudies of Astronomical Reasoning Database. Proceedings of the National Astronomy Teaching Summit, August 3, 2016, San Francisco, CA. 